\title{
A Review of the Toxicity of Compounds Found in Herbal Dietary Supplements
}

\author{
Authors \\ Affiliations \\ 1 Department of Drug Discovery and Development, \\ Harrison School of Pharmacy, Auburn University, Auburn, \\ Alabama, USA \\ 2 Department of Pharmaceutical Chemistry, Faculty of \\ Pharmacy, King Abdulaziz University, Jeddah, Kingdom of \\ Saudi Arabia \\ 3 The Procter \& Gamble Company, Cincinnati, Ohio, USA
}

Amy Hudson ${ }^{1 *}$, Elizabeth Lopez ${ }^{1 *}$, Ahmad J. Almalki ${ }^{1,2}$, Amy L. Roe ${ }^{3}$, Angela I. Calderón ${ }^{1}$

Key words

toxicity, botanical, dietary supplements, plant, compound

received November 15, 2017

revised March 31, 2018

accepted April 4, 2018

\section{Bibliography}

DOI https://doi.org/10.1055/a-0605-3786

Published online April 19, 2018 | Planta Med 2018; 84: 613626 ○ Georg Thieme Verlag KG Stuttgart · New York I

ISSN 0032-0943

\section{Correspondence}

Prof. Dr. Angela I. Calderón

Department of Drug Discovery and Development, Harrison

School of Pharmacy, Auburn University

3306 Walker Building, Auburn, AL 36849-5501, USA

Phone: + 13348448333 , Fax: + 13348448331

aic0001@auburn.edu

\section{ABSTRACT}

Use of herbal dietary supplements by the public is common and has been happening for centuries. In the United States, the Food and Drug Administration has a limited scope of regulation over marketed herbal dietary supplements, which may contain toxic botanical compounds that pose a public health risk. While the Food and Drug Administration has made efforts to prohibit the sale of unsafe herbal dietary supplements, numerous reports have proliferated of adverse events due to these supplements. This literature review investigates bioactive plant compounds commonly used in herbal dietary supplements and their relative toxicities. Using primarily the National Library of Medicine journal database and SciFinder for current reports, 47 toxic compounds in 55 species from 46 plant families were found to demonstrate harmful effects due to hepatic, cardiovascular, central nervous system, and digestive system toxicity. This review further contributes a novel and comprehensive view of toxicity across the botanical dietary market, and investigates the toxicity of the top ten botanical dietary supplements purchased in the United States of America to gauge the exposure risk of toxicity to the public. The criteria of measuring toxicity in this review (plant compound, family, quantity, and toxicity effects) across the entire market in the United States, with special attention to those supplements whose exposure to the consumer is maximal, provides a unique contribution to the investigation of botanical supplements.

\section{Introduction}

Herbal medicine has been used for centuries to cure illness and to improve quality of life. The practice of herbal medicine continues to be important in the culture of communities across the globe. An estimated four billion people living in developing countries ( $80 \%$ of the world's population) depend upon herbal medicine as a primary healthcare source [1]. The use of herbal medicine in highly developed countries has increased in recent years as healthcare costs rise. Individuals have begun to self-medicate with herbal supplements, complement their traditional practices, or utilize alternative practices such as Chinese herbal medicine, Ayurvedic medicine, and homeopathy [2].

In the 1990 s, herbal medical drugs represented $40 \%$ of all healthcare services delivered in China. In other countries, an esti- mated 48\% (Australia), 70\% (Canada), 42\% (USA), 38\% (Belgium), and $75 \%$ (France) of each respective nation's population had used herbal drugs at least once [1]. In a 2007 NHIS report, almost $40 \%$ of adults surveyed had used alternative medical therapy in the past year. Survey results showed that alternative medicine was commonly used to treat back pain, head or chest colds, neck pain, joint pain, anxiety, or depression. The most commonly used alternative medical therapy was consuming "nonvitamin, nonmineral, natural products". Some of the most popular herbal products used were Echinacea, ginseng, Ginkgo, and saw palmetto [3]. These nonvitamin, nonmineral, natural products account for the majority of out-of-pocket expenses for alternative medicine. In

* These two authors contributed equally to this work. 


$\begin{array}{ll}\text { ABBREVIATIONS } & \text { alanine aminotransferase } \\ \text { ALT } & \text { acute myocardial infarction } \\ \text { AMI } & \text { Dietary Supplement Health and Education Act } \\ \text { DSHEA } & \text { Elton B. Stephens Co } \\ \text { EBSCO } & \text { epigallocatechin gallate } \\ \text { EGCG } & \text { end-stage renal disease } \\ \text { ESRD } & \text { Food and Drug Administration } \\ \text { FDA } & \text { Food Safety Modernization Act } \\ \text { FSMA } & \text { herbal dietary supplements } \\ \text { HDSs } & \text { (1R,3S)-1-methyl-1,2,3,4-tetrahydro-[beta]- } \\ \text { MTCA } & \text { carboline-3-carboxylic acid } \\ & \text { Nordihydroguaiaretic acid } \\ \text { NDGA } & \text { National Health Interview Survey } \\ \text { NHIS } & \text { National Library of Medicine journal database } \\ \text { PubMed } & \text { serum glutamic pyruvate transaminase } \\ \text { SGPT } & \text { serum glutamic oxaloacetic transaminase } \\ \text { SGOT } & \text { triethylene glycol } \\ \text { TEG } & \text { United States of America } \\ \text { USA } & \end{array}$

the 2007 NHIS report, those who use alternative medicine spent $\$ 14.8$ billion on these products [4].

In the USA, sales have increased by $\$ 6$ billion between 2007 and 2012. Furthermore, the botanical dietary supplement market in the USA is expected to increase further in worth by 2020 as disease prevention and healthier living becomes a top concern for many Americans [5].

This industry is regulated to a limited extent in the USA. Congress passed the DSHEA of 1994 to amend the 1958 Food Additive Amendments of the Federal Food Drug and Cosmetic Act. Due to this act of legislation, many dietary supplements contain ingredients not recognized by DSHEA as a traditional nutrient, thus, allowing dietary supplement manufacturers to bypass FDA regulations [2].

Before new drugs and food additives are released on to the market, they must undergo lengthy, rigorous testing to prove product safety and efficacy. Product efficacy is investigated through human trials to demonstrate that the product will have the claimed effect on its label. These tests, along with the expense of applying to the FDA, are quite costly, and this cost presents itself to the customer at the retail counter. Botanical dietary supplement manufacturers are not mandated to undergo FDA testing; thus, this is a cost saving to the manufacturer and customer. Botanical supplements are generally much less expensive than Western medicine, providing another reason for botanical dietary supplements to be an attractive alternative or complement to Western medicine.

However, in 2011, the FSMA was passed and raised the safety standards for new ingredients in dietary supplements. Dietary supplement manufacturers must notify the FDA in advance when a new dietary ingredient will be included in a product. Dietary supplement manufacturers must now provide evidence of safety of any new dietary ingredients in order to prevent consumer health from being put at risk [6].
Although supplement manufacturers are not mandated to undergo FDA testing, manufacturers are recommended to provide scientific evidence to support any claims made in product labeling and advertisements. Since DSHEA was passed in 1994, the FDA has identified problems with supplements, and manufacturers have warned about and recalled possible harmful products [2], such as Aristolochia and comfrey. In 2004, botanical supplements containing ephedrine alkaloids were banned by the FDA due to the increased risk of stroke, heart attack, and death [7].

Furthermore, the FDA has also issued advisories on entire families of dietary supplements containing specific active ingredients. For example, the FDA issued an advisory in 2014 warning all manufacturers of supplements containing comfrey, a plant discussed in this literature, to remove this ingredient from their products. According to the FDA, the pyrrolizidine alkaloids within the herb show substantial evidence for hepatotoxicity and therefore are unsafe for ingestion [8]. This advisory proves the necessity for research and literary review in identifying hazardous dietary supplement ingredients that may call the FDA to attention and implement reform to their distribution.

Despite this increased risk, the general public, both in the USA and across the world, views herbal medicine as a natural approach to healing. Many assume these natural products are not toxic, and do not consider the possible adverse effects of improper use and unrestrained intake. Some of the botanical supplements used as herbal medicine are derived from plants not typically used for human consumption. Therefore, the safety and efficacy of these plants remain untested. For example, saw palmetto extracts have been shown to improve male urological symptoms with low adverse events compared to the prescription drug finasteride used to treat these symptoms. However, the long-term effects and overall effectiveness have yet to be determined [2]. Additionally, the increase in herbal product usage in populations that also have ready access to conventional medicines (drugs) and polypharmacy warrants more consideration of the potential for herbdrug interactions [9].

The lack of information among botanical dietary supplement manufacturers coupled with the general public's lack of risk awareness can lead to the development of severe poisoning and acute health problems in herbal medicine users [1].

In this literature review, we have compiled 49 known toxic compounds present in 53 different plant species belonging to 39 plant families with various adverse effects such as hepatotoxicity, cardiovascular toxicity, and central nervous system effects. The purpose of this review is to provide a succinct summary of known toxicity levels, usage limits, and possible health risks associated with medicinal plants and extracts derived from plants ranging across the entire herbal supplement market. Furthermore, the potential toxicity levels have been investigated for the top ten botanical dietary supplements available to consumers in the USA in order to more accurately gauge the public consumer's exposure to these toxicities. As more toxic compounds in herbal medicine undergo testing and more data becomes available through academic research, supplement manufacturers can make safer products, and the general public can make more informed health decisions. 


\section{Methods}

To compile this literature review, PubMed, EBSCO, and SciFinder ( $\vee$ Table 1 ) were primarily used to conduct searches about toxicity levels of plant compounds found within botanical dietary supplements and herbal drugs. Various search terms such as "toxic plant compounds", "herbal supplement adverse effects", "plant compound adverse effects", "toxic herbal medicine", "toxic botanical supplements", and "toxic alternative medicine" were used to maximize results. Furthermore, the scientific names of the top ten botanical dietary supplements on the market were paired with these terms to investigate the potential toxicity of products most frequently consumed by the public. These include: Curcuma longa, Triticum aestivum, Linum usitatissimum, Aloe barbadensis, Sambucus nigra, Silybum marianum, Lepidium meyenii, Withania somnifera, Echinaceae spp., and Serenoa repens [10]. If another source suggested that a specific plant species or plant compound had possible toxicity, PubMed was utilized to verify the claim by searching "(suggested plant or compound) AND toxic". If several journal articles corroborated the claim, the plant compound was included in the review. The majority of sources were derived from articles published in the past ten years (since 2007), while one source was published in 1984 and another source was published in 1976.

For a plant compound to be included in the review, these four elements were considered vital:

- An identifiable compound within the plant species or botanical dietary supplement that has been connected to the toxic effects observed

- The identity of the plant family and species from which the toxic compound originates

- The amount of the plant compound/plant species/botanical dietary supplement that was consumed when the toxic effects were observed

- A description of the toxic effects observed

Many articles lacked one or more of the elements described above. When this occurred, attempts were made to find the missing information through other database searches and using plant toxicology reference books to identify compounds and their levels in plant species. Several sources, however, had to be excluded from the study due to lack of compliance to at least one of the aforementioned criteria.

Secondary sources for this literature review included plant toxicology textbooks, reports from U.S. and European federal agencies, and databases such as NAPRALERT. Two tables have been created from the sources accumulated from this review to organize the information resulting from the aforementioned searches: one table detailing the potential toxicity levels from adverse events of the top ten most sold botanical dietary supplements on the US market, and another table detailing the information obtained from sources regarding the toxicity of plant compounds across the botanical supplement market $(\triangleright$ Tables 2 and 3, respectively).
- Table 1 Sources used in the literature search.

\begin{tabular}{|c|c|c|}
\hline Databases & Agency websites & Books \\
\hline $\begin{array}{l}\text { - LiverTox } \\
\text { - NAPRALERT } \\
\text { - PubMed } \\
\text { - TOXNET } \\
\text { - EBSCO }\end{array}$ & $\begin{array}{l}\text { - European Medicines } \\
\text { Agency (EMA) } \\
\text { Committee on Herbal } \\
\text { Products } \\
\text { - NIH National Center } \\
\text { for Complementary } \\
\text { and Integrative Health } \\
\text { - U.S. Food and Drug } \\
\text { Administration (FDA) }\end{array}$ & $\begin{array}{l}\text { American } \\
\text { Herbal Products } \\
\text { Association's } \\
\text { botanical safety } \\
\text { handbook } \\
\text { (2nd ed.) }\end{array}$ \\
\hline
\end{tabular}

\section{Results}

The possible toxic compounds were placed into categories based upon their effects. The most common effect was hepatotoxicity (15 compounds) followed by cardiovascular toxicity (12 compounds), digestive system toxicity (5 compounds), nervous system toxicity (6 compounds), renal toxicity (4 compounds), reproductive toxicity (3 compounds), endocrine toxicity (1 compound), and dermatological toxicity (1 compound) ( $\triangleright$ Tables 2 and 3 ). Twenty-three human trials and twenty-seven animal studies were accumulated in this search.

\section{Plants and plant constituents associated with hepatotoxicity}

The fifteen compounds known to be hepatotoxic are present in 20 plant species and 16 plant families. The anthraquinone emodin was found to be the most toxic of these compounds. Emodin is present in Frangula alnus Mill., a member of the Rhamnaceae family, and A. barbadensis Miller, commonly called aloe vera, a member of the Asphodelaceae family. Hepatocyte viability decreased by $30-45 \%$ when mice were orally given 40 and $80 \mu \mathrm{M}$ of pure emodin extract for $24 \mathrm{~h}$ [11]. Clinical reports of acute toxic hepatitis in humans have been reported [12-14]. Although, two research teams suspect that a hypersensitive immune response is responsible for the induction of hepatitis due to the patients' elevated levels of eosinophils $[12,14]$. However, one clinical case study detailed a woman's development of hepatitis after orally consuming $500 \mathrm{mg}$ of aloe vera leaf powder every 2-3 days for 5 years. After being admitted to the hospital and stopping the consumption aloe vera, her liver function returned to normal [12].

Overconsumption of emodin has been shown to elevate liver enzyme concentrations along with other adverse effects, such as seizures, nephritis, gastrointestinal hemorrhage, and dyspnea. However, the genus Senna contains emodin, and a maximum daily oral intake has been established for senna-based products at $34.4 \mathrm{mg}$ [15]. In vitro studies suggest that emodin significantly inhibits critical pathways in these cells, such as Toll-like receptors, MAPK, and NF- $\kappa$ B pathways [16].

According to the National Center for Complementary and Integrative Health [17], Ginkgo biloba L. of the Ginkgoaceae family, and commonly known as ginkgo, has not been linked to liver injury. Sometimes, ginkgo has even been used to treat various forms of liver injury. As stated previously, ginkgo can inhibit liver 


\begin{tabular}{|c|c|c|c|c|c|c|c|c|c|c|}
\hline 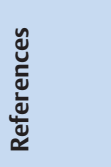 & $\begin{array}{l}\overline{6} \\
\mathbb{7} \\
\frac{1}{E} \\
\underline{E}\end{array}$ & $\widetilde{\widetilde{\sigma}}$ & $\widetilde{\widetilde{\sigma}}$ & $\begin{array}{l}2 \\
0 \\
0 \\
0\end{array}$ & $\bar{\unrhd}$ & g & 㐫 & $\overline{\bar{\Xi}}$ & $\overline{\bar{\Xi}}$ & $\stackrel{\infty}{\unrhd}$ \\
\hline 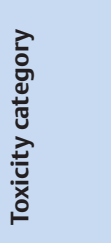 & 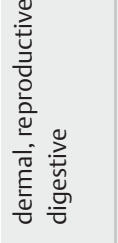 & 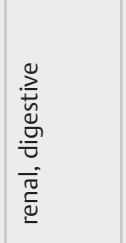 & 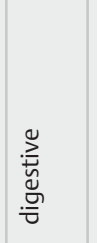 & 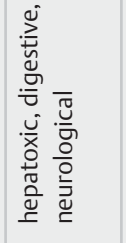 & 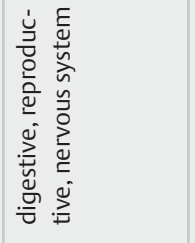 & 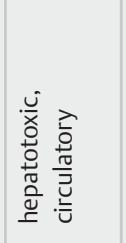 & 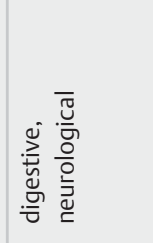 & 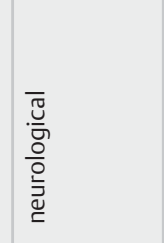 & 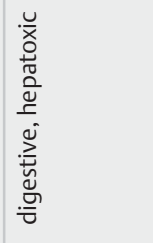 & 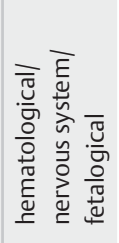 \\
\hline 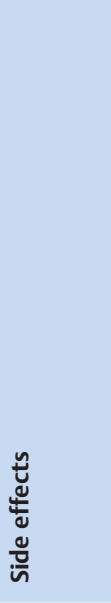 & 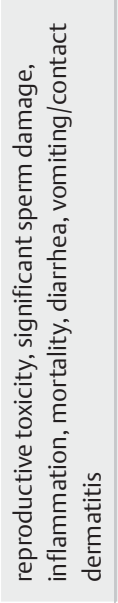 & 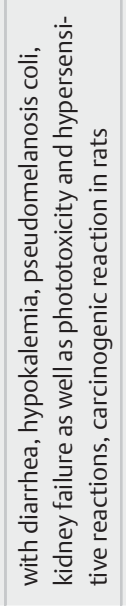 & 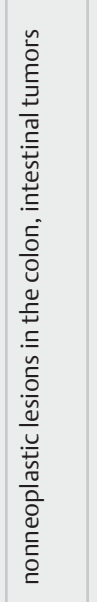 & 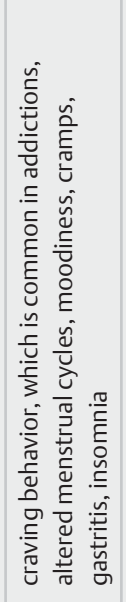 & 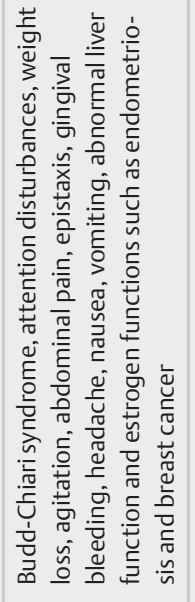 & 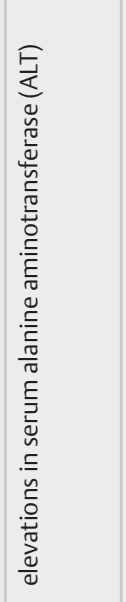 & 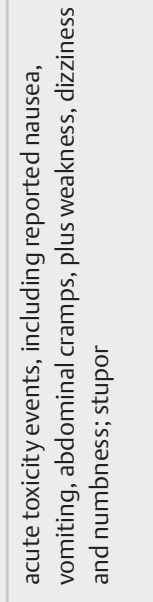 & 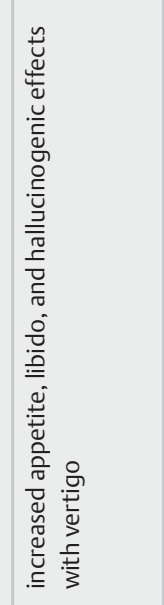 & 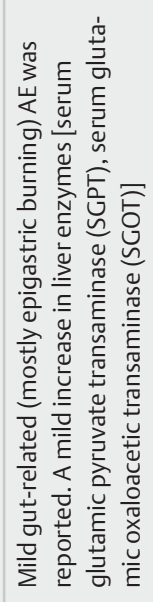 & 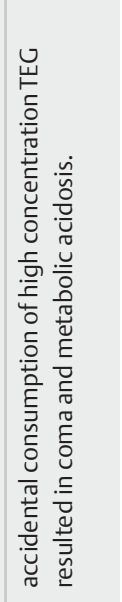 \\
\hline せ气 & 苋 & 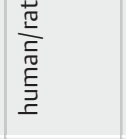 & $\stackrel{\mathscr{U}}{\bar{E}}$ & 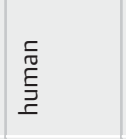 & 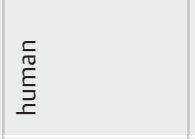 & $\overrightarrow{\widetilde{T}}$ & 䲶 & $\begin{array}{l}\text { 䔍 } \\
\text { 至 }\end{array}$ & 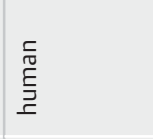 & 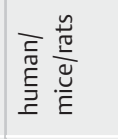 \\
\hline 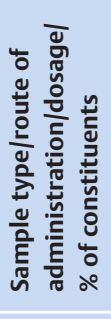 & 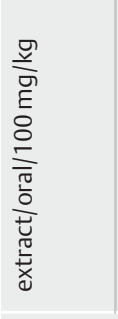 & 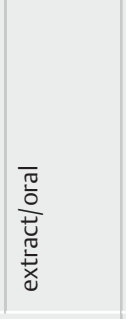 & 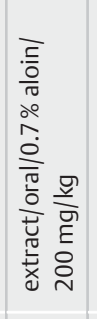 & 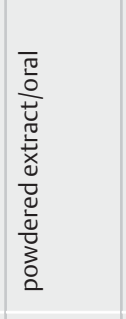 & 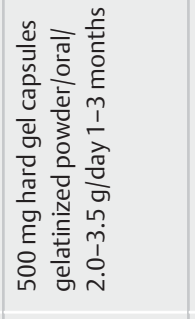 & 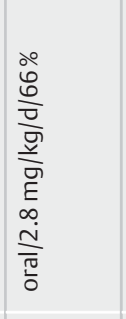 & 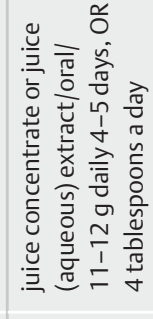 & 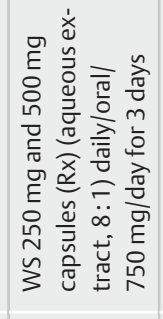 & 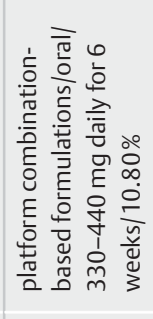 & \\
\hline $\begin{array}{l}\frac{1}{0} \\
\text { L } \\
\frac{1}{0} \\
\frac{\pi}{2}\end{array}$ & $\begin{array}{l}\frac{\frac{\pi}{0}}{\frac{0}{0}} \\
\frac{0}{3}\end{array}$ & & 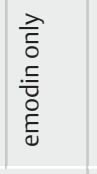 & ○。 & 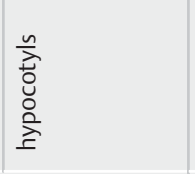 & 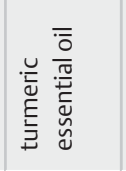 & 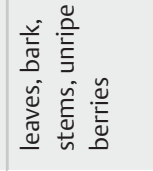 & $\begin{array}{l}\frac{\bar{c}}{0} \\
\frac{0}{2} \\
\frac{0}{0} \\
\frac{\frac{\pi}{3}}{3}\end{array}$ & 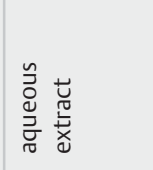 & 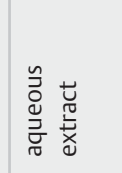 \\
\hline 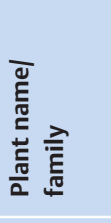 & 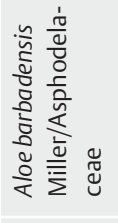 & & & 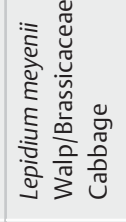 & & 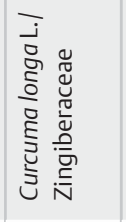 & 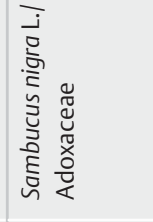 & 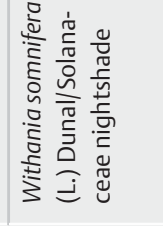 & & \\
\hline 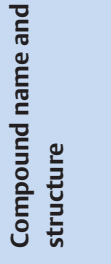 & 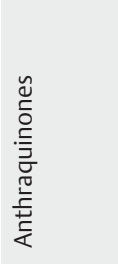 & & & 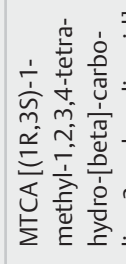 & & 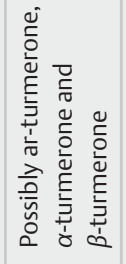 & 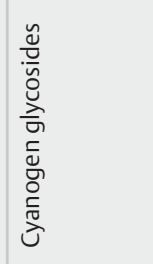 & & & 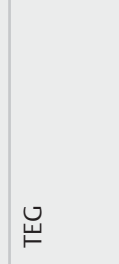 \\
\hline
\end{tabular}




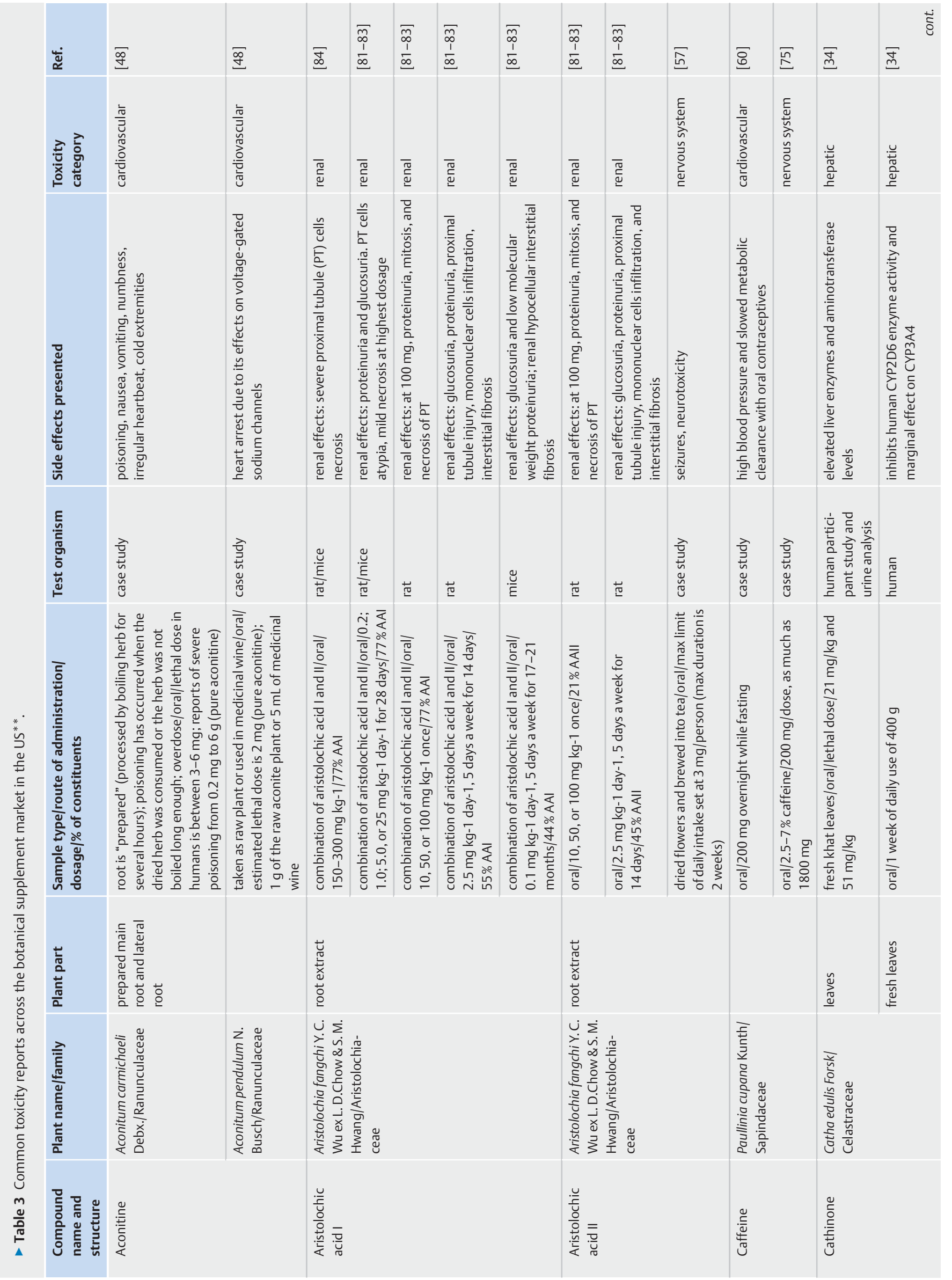

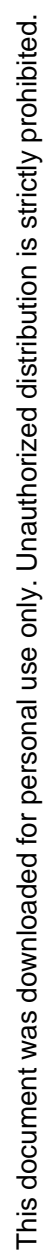




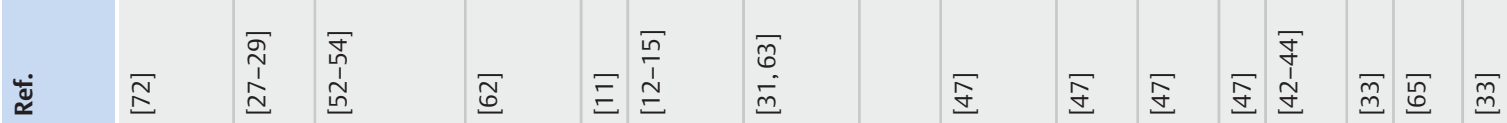

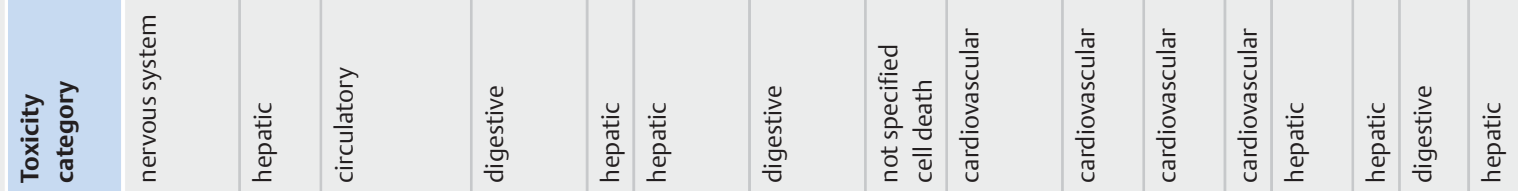
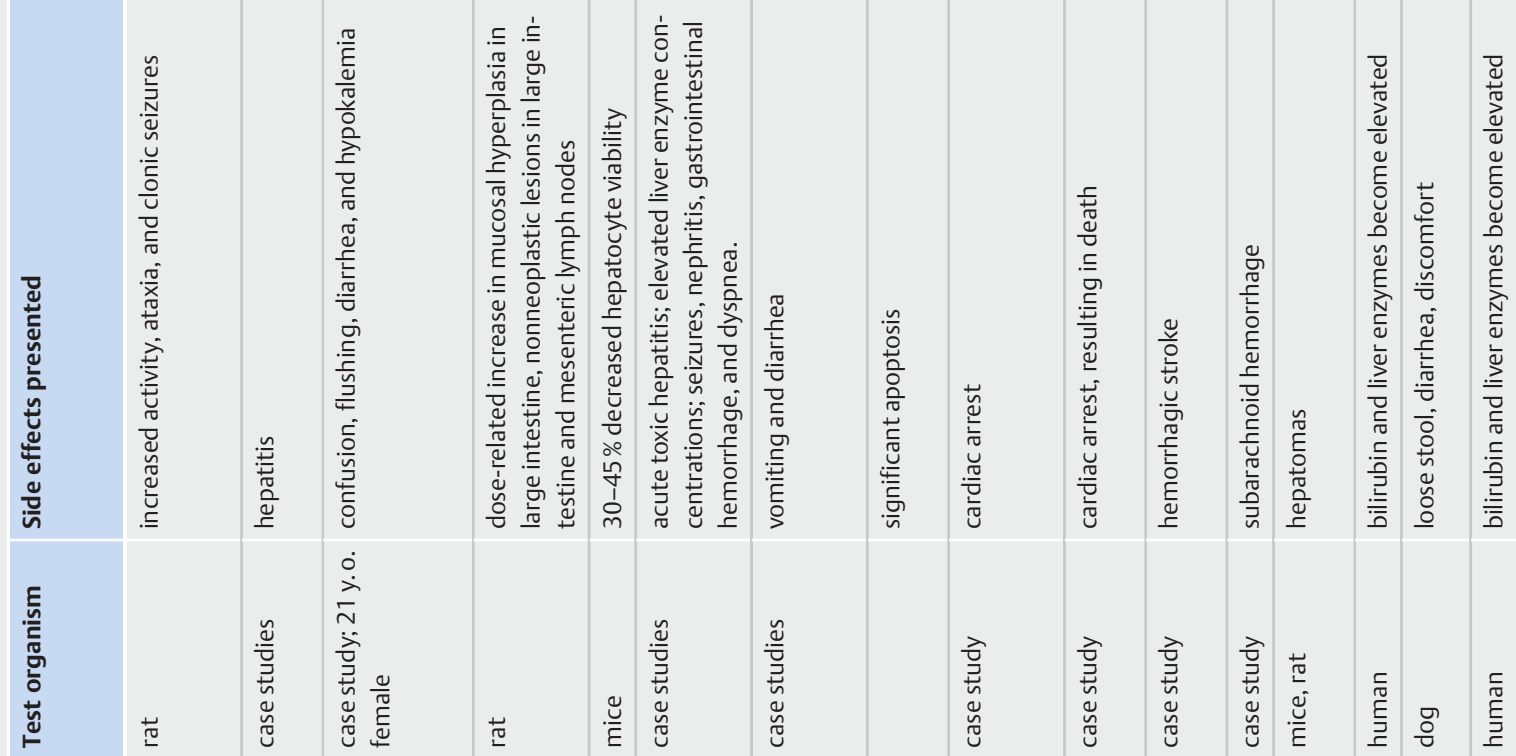

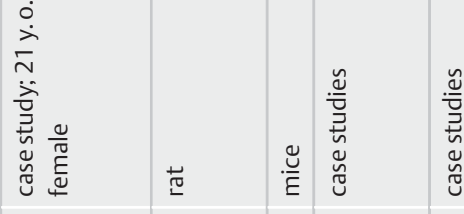
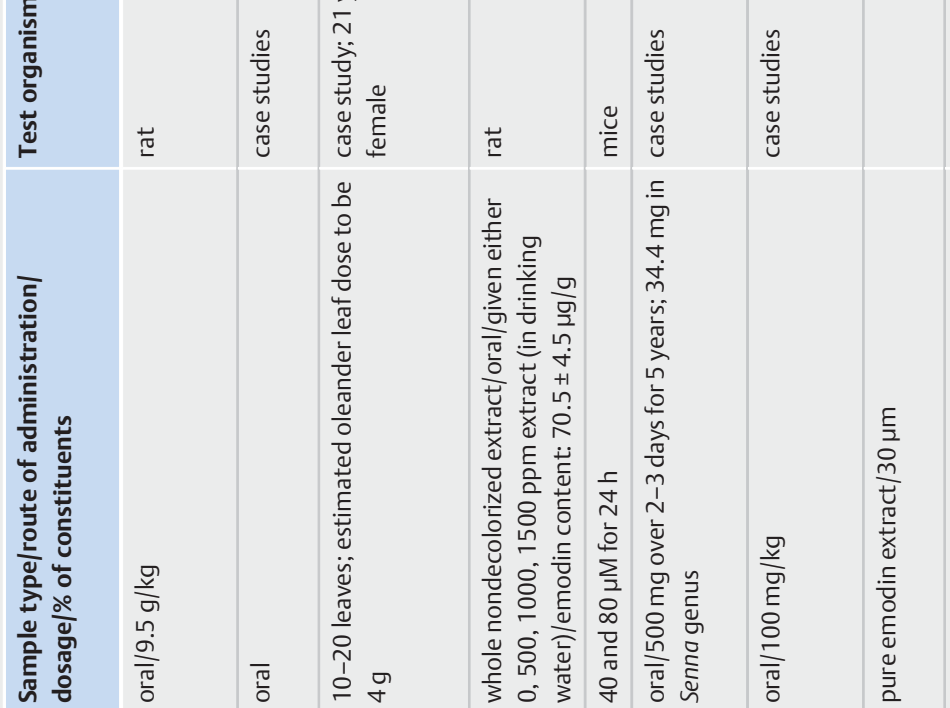

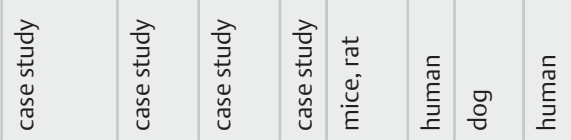

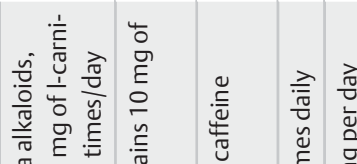

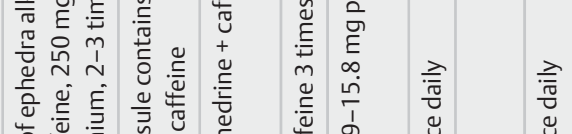




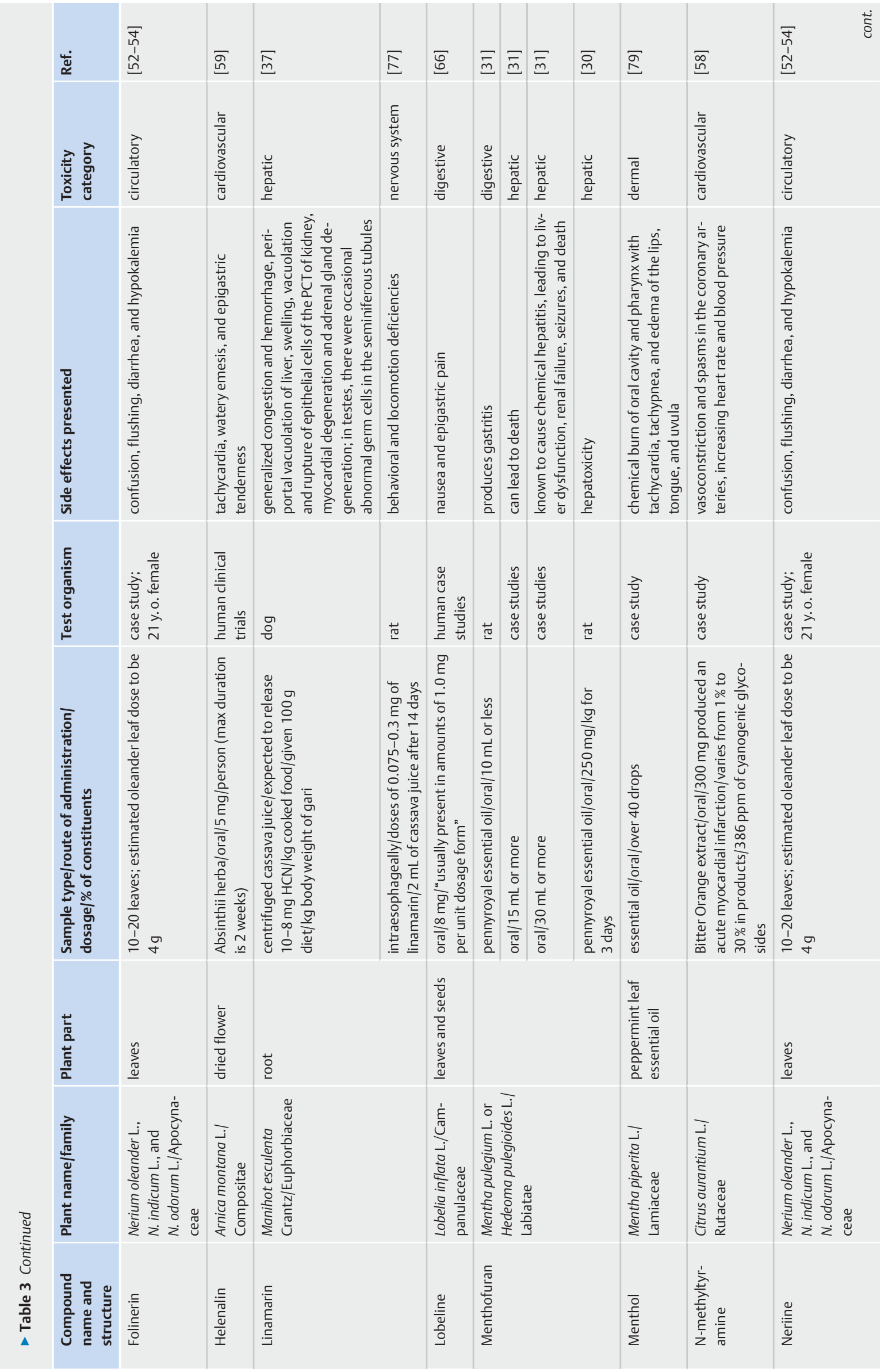




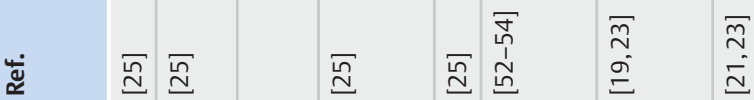

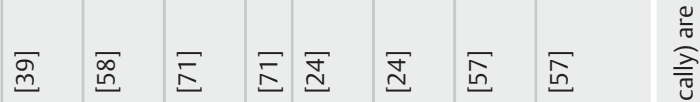

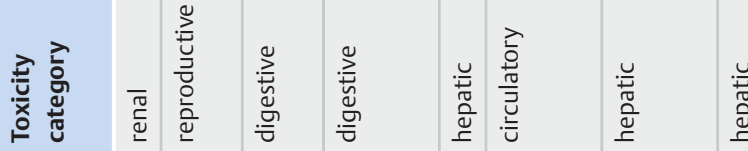

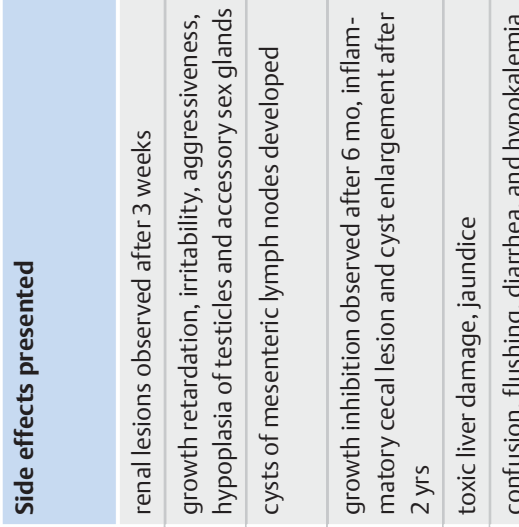
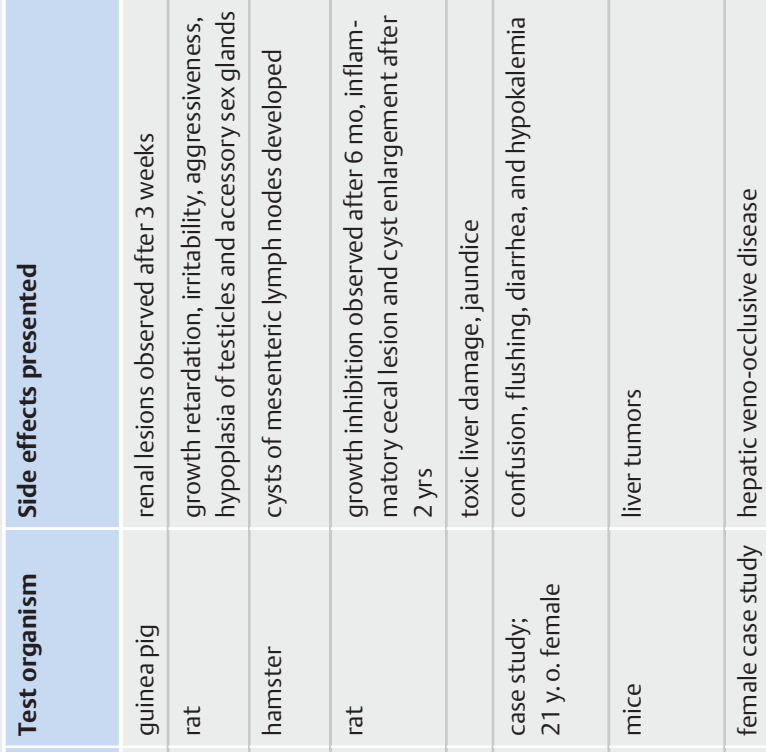

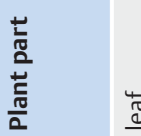

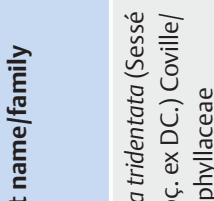

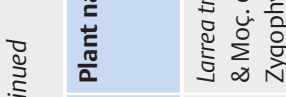

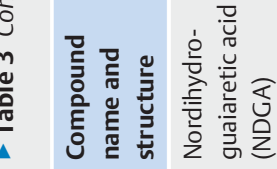
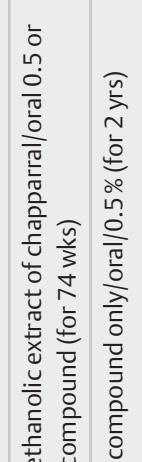

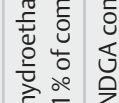

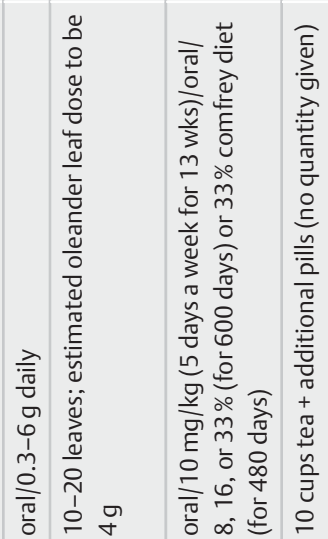

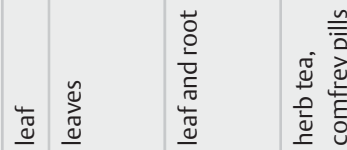

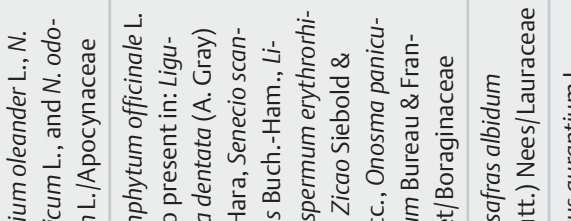

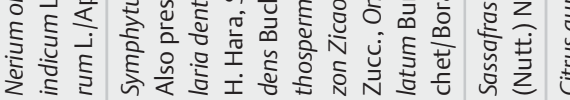

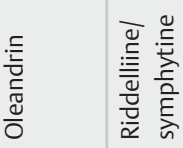

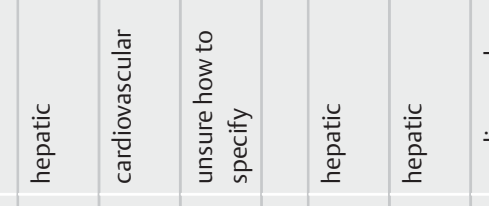

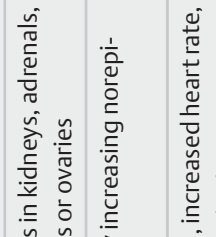

高总

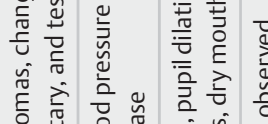

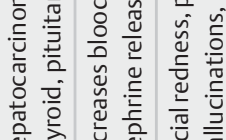

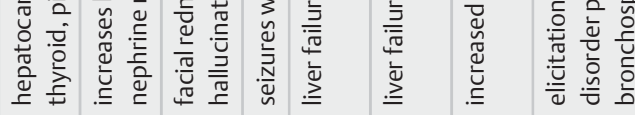

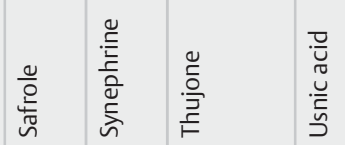

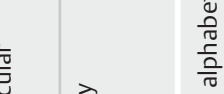

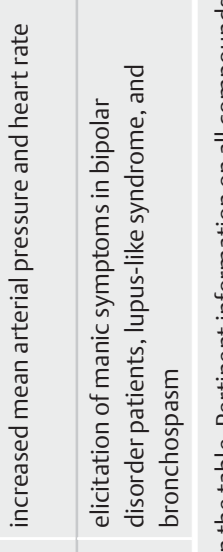

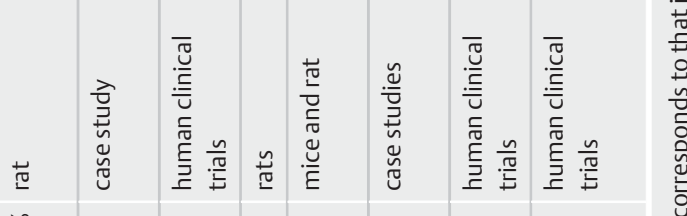

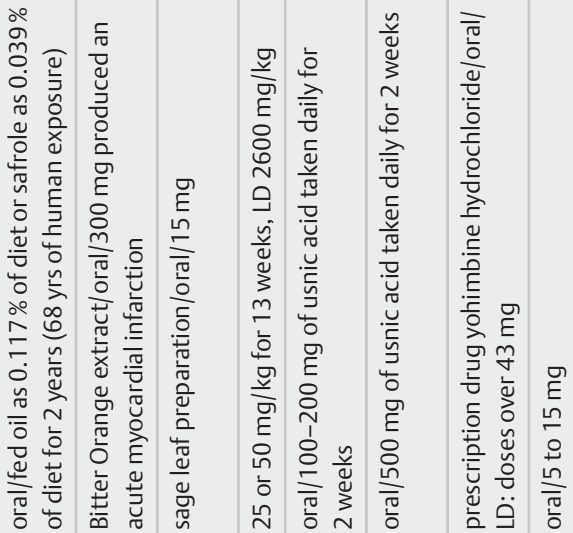

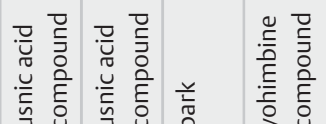

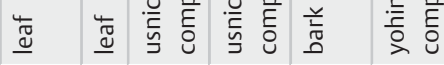

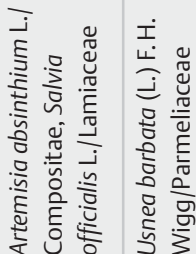

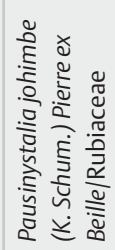

高芯 $\sum_{3}^{\infty}$

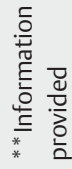


enzyme activity in vitro, but when consumed by humans, ginkgo does not impact drug metabolism [18].

Pyrrolizidine alkaloids riddelliine and symphytine are compounds present in Symphytum officinale, commonly known as comfrey. This plant species is a member of the Boraginaceae family. When rats were orally given $10 \mathrm{mg} / \mathrm{kg}$ body weight for 5 days per week for 13 weeks, the animals experienced hepatopathy [19]. In one case study, a woman drank as much as 10 cups of comfrey herb tea in one day, along with taking comfrey pills, and developed hepatic veno-occlusive disease [20]. According to the U.S. National Library of Medicine's LiverTox database [21], cases of acute liver injury have been reported, usually beginning after 1 to 2 months of consuming comfrey. However, the database states comfrey hepatotoxicity is rare because consumption of comfrey is restricted or banned in many countries due to the knowledge of possible liver injury [21].

Pyrrolizidine alkaloids are also commonly found in the plants Ligularia dentata, Senecio scandens, Lithospermum erythrorhizon, and Onosma paniculatum. Because of the known liver toxicity demonstrated by these plants, pyrrolizidine alkaloids are banned in the USA and limited in Europe to $100 \mu \mathrm{g}$ per day externally or $1 \mu \mathrm{g}$ per day internally for no more than 6 weeks [22]. However, the European Medical Agency's Committee of Herbal Medical Products [23] recommends a daily intake of no more than $0.35 \mu \mathrm{g}$ per day to avoid the risk of long-term toxicity affects.

Usnic acid is a dibenzofuran derivative present in Usnea barbata (L.) F. H. Wigg. of the Parmeliaceae family. Mice and rats were orally given 100 and $200 \mathrm{mg} / \mathrm{kg}$ body weight during a 2-week study. These animals experienced liver toxicity. Human case studies have shown that taking $500 \mathrm{mg}$ of usnic acid for 2 weeks can induce liver failure [24].

NDGA is an antioxidant compound present in Larrea tridentata of the Zygophyllaceae family and is commonly known as creosote bush. Human case reports suggest that consuming $0.3-6 \mathrm{~g}$ daily of $L$. tridentata tablets can lead to toxic liver damage with jaundice. In guinea pigs, a lethal oral dose of NDGA is $0.8 \mathrm{~g} / \mathrm{kg}$ body weight $[25,26]$.

The isoquinoline alkaloid chelidonine is present in Chelidonium majus L. of the Papaveraceae family, also known as greater celandine. The presentation of hepatitis after celandine use has been mentioned in several human case studies [27-29].

Menthofuran is a compound present in pennyroyal oil, derived from Mentha pulegium or Hedeoma pulegioides of the family Labiatae. Rats were orally given $250 \mathrm{mg} / \mathrm{kg}$ of pennyroyal oil once daily for 3 days. These rats experienced hepatotoxicity [30]. Consumption of $30 \mathrm{~mL}$ or more of pennyroyal oil can cause hepatitis, leading to further liver dysfunction in humans [31].

Flavocoxid is a proprietary blend of baicalin and catechins. Baicalin is a compound from Scutellaria baicalensis (Lamiaceae) and the catechins are from Acacia catechu (Leguminosae). Baicalin has shown hepatoprotective activity in multiple animal and in vitro experiments [32]. EGCG is present in green tea extract, and it is believed that EGCG is responsible for hepatotoxicity attributed to green tea extract. EGCG is also present in flavocoxid, and researchers infer this catechin is responsible for liver injury caused by flavocoxid as well [32]. Limbrel is a flavocoxid commercial product derived from the bioflavonoids baicalin and catechins that have been ground into tablets. When humans orally consume 250-500 mg of Limbrel twice daily, bilirubin and liver enzymes become elevated [32].

When human participants orally consumed $400 \mathrm{~g}$ of Catha edulis (khat) leaves (of the Celastraceae family) daily for a week (a dose demonstrative of frequent use of the leaves as a supplement), studies showed decreased activity of CYP2D6, a liver enzyme involved in metabolism [33]. The stimulant cathinone is a monoamine alkaloid present in the leaves of khat. In other case reports, toxic effects of khat use appear years later with elevated liver enzymes and aminotransferase levels, indicating the presence of liver damage [34]. An Australian case report [34] suggests that khat-associated hepatitis may be due to an autoimmune response. Khat is native to East Africa, and according to one paper [35], no khat-induced hepatitis has been reported. The toxicity may be the result of contaminants used to preserve khat during exportation, or hepatitis may be caused by individual abuse of drugs and alcohol [35]. Notably, the legal restriction on khat distribution commercially in the USA may limit its use by the public consumer [36]; however, improvised preparations and its use elsewhere highlight it as a supplement for investigation in this review.

Linamarin is a cyanogenic glucoside present in Manihat esculenta (Euphorbiaceae), known as cassava. The plant is often consumed in the West African food known as gari. Dogs were given $100 \mathrm{~g} / \mathrm{kg}$ of gari over 14 weeks and liver vacuolation was observed in the test subjects [37]. Cassava is known as a cause of nonalcoholic chronic pancreatic disease in developing nations [38].

Safrole, an alkenylbenzene, is a phenylpropene present in Sassafras albidum (Lauraceae), commonly known as sassafras, and Foeniculum vulgare, commonly known as fennel. This plant has been used by the public primarily through sassafras essential oil. In one study, rats consumed sassafras oil as $0.117 \%$ of their diet or safrole as $0.039 \%$ of their diet for 2 years. Researchers calculated this would be the equivalent to humans consuming sassafras oil/safrole for 68 years. Among many adverse effects observed, hepatocarcinomas developed on the test subjects [39].

Alpha- and beta-turmerones are active compounds present in the essential oil of $C$. longa (Zingiberaceae), commonly called turmeric. In a rat model study, oral administration of $2.8 \mathrm{mg} / \mathrm{kg}$ per day resulted in elevated serum ALT in the liver, indicating the presence of liver damage [40].

W. somnifera, commonly known as ashwagandha and a member of the nightshade family, is commonly used as an herbal supplement in Ayurvedic medicine. In one clinical study, consumption of $330-440 \mathrm{mg}$ a day for 6 weeks resulted in mild epigastric burning, as well as an increase in liver enzymes (SGPT and SGOT), indicating hepatic distress [41].

Estragole is an alkenylbenzene derived from F. vulgare, commonly known as fennel, of the Apiaceae family. Estragole has been known to induce hepatomas in rodents at high doses. These tumors are caused by the bioactivation by cytochrome P450s and sulfotransferases, giving rise to the ultimate carcinogenic metabolite 1'-sulfooxyestragole, which forms DNA adducts [42]. Indeed, in vitro studies of growing cell lines of human hepatomas have determined that activation of CYP1A2 and CYP2A6 enzymes ultimately lead to the formation of 1'-sulfooxyestragole, which is un- 
stable in aqueous environment and whose carbocation formed in solution reacts easily with DNA in the liver [43]. The margin of exposure of alkenylbenzenes such as estragole and safrole to cytotoxicity due to fennel consumption was calculated at 1.9$15.8 \mathrm{mg}$ per day to be less than 10 , meaning that daily intake was enough to cause genotoxicity and carcinogenic events in experimental animals, indicating the risk to human health and priority for risk management $[43,44]$.

\section{Plants and plant constituents associated with cardiovascular toxicity}

The literature has indicated that 12 compounds are known to exhibit cardiovascular toxicity. These compounds belong to 12 plant species and 9 families.

Ephedrine is an alkaloid with a phenethylamine skeleton found in various plants within the genus Ephedra (Ephedraceae). Ephedrine is a bronchodilator used to prevent low blood pressure during spinal anesthesia. Ephedrine is also found in dietary supplements that promote short-term weight loss, but those are now illegal in the USA. However, in traditional Chinese medicines that contains ephedrine (ma-huang), it is legal.

The ephedrine quantity in dietary supplements taken orally is about $20 \mathrm{mg}$ per serving, and doses are taken up to two to three times per day. It has been shown that labels of dietary supplements do not list ephedrine content, or incorrectly report the amount of ephedrine in these products [45].

Ephedrine has been associated with cardiovascular dysfunction such as myocardial infarction, severe hypertension, myocarditis, and lethal cardiac arrhythmias [46]. The typical dose of ephedrine used for bronchodilation is $25-50 \mathrm{mg}$, but ephedrine doses associated with adverse events were less than this amount.

Four selected case studies were featured in the Haller and Benowitz paper [47]. One patient consumed a dietary supplement (Shape-Fast Plus) for 1 week and suffered a subarachnoid hemorrhage. Shape-Fast Plus was taken as a capsule three times a day before meals for weight loss. Each capsule contained $12 \mathrm{mg}$ of ephedra alkaloids, along with $40 \mathrm{mg}$ of caffeine. Another patient suffered a hemorrhagic stroke 90 min after consuming Ultimate Orange, a drink containing $415 \mathrm{mg}$ of ephedra alkaloids and caffeine. This patient had also run 3 miles before the hemorrhagic stroke occurred. The last two cases feature a dietary supplement known as Ripped Force. Both patients went into cardiac arrest. The first patient was on asthma medications (albuterol and theophylline) and had consumed an 18-oz. bottle of Ripped Force before cardiac arrest occurred. The patient was drinking up to three Ripped Force bottles a day for an undisclosed amount of time. Each 18-oz. drink contained $20 \mathrm{mg}$ of ephedra alkaloids, $100 \mathrm{mg}$ of caffeine, $250 \mathrm{mg}$ of L-carnitine, and $240 \mu \mathrm{g}$ of chromium. The interaction of the theophylline and albuterol medications with the caffeine and ephedra in Ripped Force caused an arrhythmia that induced cardiac arrest. The next patient had taken two Ripped Force capsules each morning for 1 year. Each capsule contains $10 \mathrm{mg}$ of ephedrine and $100 \mathrm{mg}$ of caffeine. After a 20-min jog and consuming Ripped Force capsules for 1 year, this patient collapsed suffering a cardiac arrest, resulting in death. A case study by Haller and Benowitz indicates that caffeine "enhances the cardiovascular and central nervous system effects of ephedrine" [47].

Aconitine is a toxic compound found in the genus Aconitum (Ranunculaceae). Aconitum carmichaeli Debx. is a plant commonly used in traditional Chinese medicine. The prepared main root is called chuan wu, and fu zi is the prepared lateral root. These roots are prepared by boiling this herb for several hours. Poisoning has occurred when either the unprepared dried herb was consumed, herbs were boiled for an insufficient amount of time, or patients overdosed [48]. The lethal oral dose of $A$. carmichaeli prepared roots for humans is estimated to be $3-6 \mathrm{mg}$. However, severe poisoning has been reported after consuming anywhere from $0.2 \mathrm{mg}$ to $6 \mathrm{~g}$ orally. Poisoning symptoms include nausea, vomiting, numbness, irregular heartbeat, and cold extremities [48]. Aconitum pendulum Busch is a plant that is consumed either as a raw plant or contained in medicinal wine. The estimated human lethal dose of the raw aconite plant is $1 \mathrm{~g}$ or $5 \mathrm{~mL}$ of medicinal wine. Overdoses related to this plant induced heart arrest due to its effect on voltage-gated sodium channels. The changes in sodium channels have been linked to aconitine [48]. Furthermore, aconitine has been known to inhibit the binding of acetylcholine and epinephrine to cholinergic and adrenergic receptors, respectively, in cardiac muscle cells, which may contribute to arrhythmic heart contraction [49].

Strychnine is a toxic, crystalline alkaloid that is most commonly found in the seeds of Strychnos nux-vomica L. (Loganiaceae). Strychnine causes its toxicity by interfering "with post-synaptic inhibition mediated by glycine in the brain and spinal cord" [50]. Although strychnine is an ingredient in rodent poison, it is also used in Tibetan medicine and Chinese folk medicine. If 30$120 \mathrm{mg}$ of strychnine are consumed, it can be deadly toxic. In certain instances, children have consumed less than $10 \mathrm{mg}$ and adults have consumed less than $16 \mathrm{mg}$, resulting in fatalities [50]. In one fatal case study, a patient ingested taupicine, a mole poison that was $10 \%$ strychnine. The blood sample from the patient contained $0.29 \mu \mathrm{g} / \mathrm{mL}$ of strychnine [51]. In another case, a patient ingested three teaspoons of strychnine (along with $15 \mathrm{mg}$ of methocarbamol), and $0.8 \mathrm{mg} / \mathrm{L}$ of strychnine was found in the patient's blood sample. After ingesting strychnine, the patient exhibited tachycardia, hypertension, and intense muscle spasms [51].

Neriine, oleandrin, folinerin, and digitoxigenin are cardiac glycosides found in a number of plants that are commonly known as oleander, including Nerium oleander, Nerium indicum, and Nerium odorum (Apocynaceae). These cardiac glycosides are found in all parts of the plant. A 21-year-old female consumed 10-20 $N$. oleander leaves, resulting in confusion, flushing, diarrhea, and hypokalemia. The treating physicians estimated the lethal dose of oleander leaves to be $4 \mathrm{~g}$. They formulated this estimation from the assumed volume of distribution of the glycosides in oleander leaves $(1 \mathrm{~L} / \mathrm{kg})$ and the calculated lethal dose absorbed by their patient $[52,53]$. Case studies with similar results have been reported [52-54].

These cardiac glycosides work by inhibiting $\mathrm{Na}^{+} / \mathrm{K}^{+}$ATPase pumps, causing an accumulation of intracellular sodium in myocytes. This increase in intracellular sodium inhibits the exchange of sodium and calcium, resulting in an increase of intracellular cal- 
cium. The change in calcium concentration decreases the heart rate and enhances cardiac contraction. All of these changes can result in conduction block, ventricular arrhythmias, and asystole [55].

Through searching various databases, known toxic concentrations of the individual cardiac glycosides mentioned could not be identified. This may be due to the scant commercial availability of oleander to the consumer in USA markets. This is an area of research that warrants further investigation since various decoctions of oleander preparations are available online [56].

Yohimbine is an indole alkaloid that is found in the bark of the Pausinystalia yohimbe tree (Rubiaceae). Supplements containing yohimbine have been marketed as products that can improve sexual function, but certain dosages can increase or decrease systemic blood pressure. In human clinical trials of yohimbine hydrochloride, doses of 20 to $40 \mathrm{mg}$ resulted in a moderate increase in blood pressure, and doses over $45 \mathrm{mg}$ increased mean arterial pressure and heart rate. Yohimbine compounded was given in human and animal trials. After humans were given $5-15 \mathrm{mg}$, bipolar disorder patients exhibited manic symptoms, while other patients experienced lupus-like syndrome and bronchospasms. In animal studies with mice, the oral lethal dose was determined to be $43 \mathrm{mg} / \mathrm{kg}$ [57].

Citrus aurantium (Rutaceae) is the source of bitter orange extract. After the FDA banned ephedra from weight loss supplements, many manufacturers began using bitter orange extract and guarana as substitutes. Two of the active components in bitter orange extract are synephrine and N-methyltyramine. Synephrine is the main ingredient thought to enhance weight loss by suppressing appetite and boosting metabolism. Synephrine is also known to cause "vasoconstriction and spasms in the coronary arteries, increasing heart rate and blood pressure" [58]. The amount of synephrine in these products varies from $1 \%$ to $30 \%$. Another active component, $\mathrm{N}$-methyltyramine, increases blood pressure due to increasing norepinephrine release [58]. The combining effects of these two components may cause potential cardiotoxicity.

In a case study, one patient had orally consumed 300 mg of bitter orange extract daily and suffered an AMI. The treating physicians suspected bitter orange extract was the cause of it. Researchers advise that more evidence about the safety of this extract and its components be provided before these supplements are purchased over-the-counter [58].

Helenalin, is found in the Arnica genus. Helenalin, a sesquiterpene lactone, is a known toxin in Arnica montana (Compositae), which inhibits platelet aggregation. In one case study, a patient had dissolved dried flowers in oil and topically applied them to heal bruises. Then, the patient ingested the flowers in a cup of tea. Two hours after drinking the tea, the patient experienced tachycardia, watery emesis, and epigastric tenderness. After receiving intravenous fluids and antiemetics, the patient was stabilized [59].

Turmerones found in C. longa (Zingiberaceae), previously described for its hepatotoxic qualities, has also presented acute anemia when $2.6 \mathrm{mg} / \mathrm{kg}$ per day were administered orally to rats. Inadequate oxygenation in this case may, therefore, pose a keen circulatory risk in human cases [40].
Caffeine derived from Paullinia cupana, commonly known as guarana of the Sapindaceae family, is an ingredient commonly used in energy drinks and beverages. In a clinical trial, eight healthy adults received a single dose of $200 \mathrm{mg}$ caffeine after an overnight fast. After plasma and urine samples were obtained, and heart rate and blood pressure were monitored for $14 \mathrm{~h}$, it was found that blood pressure increased significantly to a maximum of $14 \mathrm{mmHg}$. In addition, metabolic clearance was slowed in those patients taking oral contraceptives, indicating that drugbotanical interactions could pose a greater risk for toxicity due to caffeine [60]. In one study, active fractions from dried guarana seed extract used in soft drinks were subject to liquid-chromatography mass-spectroscopy and analyzed for content. It was suggested that complexes containing caffeine and catechins (and their dimers) might be responsible for antiplatelet aggregatory activity, which may be causing such a drastic increase in blood pressure [61].

\section{Plants and plant constituents associated with toxicity to the digestive system}

Five plant compounds and eight plant species from seven plant families were found to cause toxicity events.

Menthofuran, a compound mentioned previously in this review as hepatoxic, has also been found to induce adverse effects on the digestive system. M. pulegium, (Lamiaceae), naturally produces menthofuran. Menthofuran is found in many essential oils, including pennyroyal. Case studies have shown that ingesting $10 \mathrm{~mL}$ or less of pennyroyal oil can cause gastritis [31].

Emodin is another compound categorized as hepatotoxic, but has effects on the digestive system as well. This compound is found in A. barbadensis (Asphodelaceae), known as aloe vera. The National Toxicology Program conducted toxicity studies on various plant extracts. When rats were orally given aloe vera whole, nondecolorized extracts, a dose-related increase in mucosal hyperplasia in the large intestine occurred, while nonneoplastic lesions in the large intestine and mesenteric lymph nodes were also observed. The emodin content of the aloe whole leaf extract is estimated to be $70.5 \mu \mathrm{g} / \mathrm{g}$. Researchers suggest the intestinal tumors developed due to the anthraquinone emodin being transformed into mutagenic components in the intestine. The recommended dose per day for humans is $0.43 \mathrm{mg} / \mathrm{kg}$ or about 10 $30 \mathrm{mg} /$ day [62]. According to the U.S. National Library of Medicine Toxicology Data Network, mild toxic overdoses of emodin can induce vomiting and diarrhea, but severe overdoses can result in gastrointestinal hemorrhage [15]. For example, in one experiment, oral administration of $100 \mathrm{mg} / \mathrm{kg}$ whole leaf aloe extract resulted in vomiting and diarrhea [63-64].

Scutellaria baicalensis, a member of the Lamiaceae family, is commonly known as Chinese skullcap. A $5 \mathrm{~g} / \mathrm{kg}$ extract of Chinese skullcap was given to dogs over an 8-week period, and loose stool was observed as a result. Diarrhea and stomach discomfort have been observed in human case reports. Dose and preparation, unfortunately, were not reported [65].

NDGA is a compound that has been previously discussed in this paper for its hepatotoxic activity. When NDGA was isolated, it induced abnormalities in the gastrointestinal tract. Rats received an oral administration of NDGA extract for 74 weeks ( 0.5 or $1 \%$ of the 
extract was NDGA). After these administrations, mesenteric lymph node cysts developed in the test subjects. In another study, rats were given an extract $(0.5 \%$ of the extract was NDGA) for 2 years. Following this time period, inflammatory cecal lesions and cyst enlargement occurred [25]. These findings correspond with reports of renal and hepatotoxicity in humans after longterm use of NDGA and its origin, L. tridentata [26].

Lobeline is an alkaloid found in Lobelia inflata, also known as "Indian tobacco". L. inflata is a member of the Campanulaceae family. Lobeline is found in the leaves and seeds of this plant. When commercially sold, lobeline is present in a 1-mg per unit dosage. When humans consume $8 \mathrm{mg}$ of lobeline, nausea and epigastric pain was reported [66]. Lobeline has been known as a ligand for nicotinic acetylcholine receptors that competitively inhibits acetylcholine binding to smooth muscle tissue to induce peristalsis [67].

Sambucus nigra, commonly known as European elderberry, comes from the Adoxaceae family. Elderberry leaves, bark, stems, and unripe berries are known to contain cyanogen glycosides, which commonly present toxic events in clinical cases and may present in Sambucol, a syrup product made from elderberry juice concentrate. Oral consumption in human cases at $11-12 \mathrm{~g}$ daily for 4-5 days, or 4 tablespoons a day, has resulted in reports of nausea, vomiting, abdominal cramps, weakness, dizziness, numbness, and stupor [68].

L. meyenii, commonly known as maca and is a member of the cabbage family, possess a root commonly ground or extracted for human consumption as a sexual and reproductive enhancing supplement. One active compound attributed to this altered sexual behavior and reported in toxicity and adverse events includes MTCA. Consumption of a powdered root extract containing MTCA has resulted in cramps and gastritis [69]. Furthermore, according to a literature review of clinical trials associated with maca, oral consumption of 2.0-3.5 g per day in the form of $500 \mathrm{mg}$ hard gel powder extract tablets of maca primary leaves for 1 to 3 months resulted in weight loss, abdominal pain, nausea, and vomiting [70].

\section{Plants and plant constituents associated with neurotoxicity}

Six compounds from six species and six families were associated with neurotoxicity.

Thujone is a compound present in Artemisia absinthium (Compositae) and Salvia officialis (Lamiaceae), commonly known as sage leaf. In 2012, the European Medicines Agency issued a statement about the safety of thujone in herbal medicinal products. The EMA concluded the maximum limit of daily oral intake for Absinthii herba was established at $3 \mathrm{mg} /$ person and S. officialis was limited to $5 \mathrm{mg} /$ person. Both herbal products should only be used for 2 weeks maximum. The report assessed that low-dose exposure to thujone (3-7 mg/day) may be safe, but higher concentrations of thujone may pose a risk.

When rats consumed thujone in higher concentrations (concentrations of 25 or 50 and greater $\mathrm{mg} / \mathrm{kg}$ for 13 weeks), seizures were observed. In other animal studies, rats were given various doses of sage essential oil. A lethal (oral) dose was determined to be $2600 \mathrm{mg} / \mathrm{kg}$. When humans consume higher doses (15 mg), subtle changes in attention and mood were observed [71].

Caulosaponin is present in blue cohosh, Caulophyllum thalictroides (Berberidaceae). This compound has been isolated and a lethal dose has been determined. In neonates born to women who have taken blue cohosh, perinatal stroke, acute myocardial infarction, congestive heart failure, multiple organ injury, and neonatal shock have occurred. After orally consuming blue cohosh, patients experienced side effects including diarrhea, increased levels of blood pressure and blood glucose, and stomach cramps. These adverse events are believed to be caused by the toxic alkaloid methylcytisine [72,73]. A biochemical study of the constituents in blue cohosh revealed that all studied dietary supplements of blue cohosh contain N-methylcytisine [74].

The seeds and fruit of guarana ( $P$. cupana, Sapindaceae) are often a source of caffeine for herbal supplements, as previously mentioned. In a case study, a weight loss supplement contained $2.5-7 \%$ caffeine $(200 \mathrm{mg} /$ dose $)$. If patients choose to self-medicate and increase supplement usage, patients may consume as much as $1800 \mathrm{mg}$ of caffeine [74]. The safety limit recommended by the FDA for daily caffeine consumption is only $400 \mathrm{mg}$, or the equivalent of four to five cups of coffee [75].

Linamarin, previously featured as a hepatotoxic compound of Manihat esculenta (Euphorbiaceae), has been associated with neurotoxicity in animals. In an animal study where cassava-fed animals were compared to control animals, cyanide-fed animals, and malnourished animals, researchers found motor coordination of the cassava-fed animals was similar to the other groups studied. However, the plasma thiocyanate concentration as well as urinary thiocyanate excretion and elevated urinary protein excretion for the cassava-fed animals differed from all other studied groups. Researchers concluded that neurotoxicity could be a result of linamarin [76]. Another study featuring Wistar rats corroborates these findings. After consuming doses of $0.075-$ $0.3 \mathrm{mg}$ of linamarin in 2 milliliters of cassava juice for 2 weeks, the test subjects experienced behavioral and locomotion deficiencies [77].

L. meyenii, or maca, has been previously mentioned for its digestive toxicity. Human consumption of the root extract has also been associated with a significant impact on neurological functions, resulting in side effects that include craving behavior, moodiness, and insomnia [69]. Consumption of the primary leaf extract in the form of hard gel powder extract tablets at 2.5$3.0 \mathrm{~g} /$ day for 1 to 3 months has also produced reports of headaches, attention disturbances, and agitation [70].

W. somnifera (nightshade), previously mentioned for its hepatotoxic properties, contains the active compound TEG, which at accidental high concentrations in humans has resulted in coma and metabolic acidosis [78]. Similar neurological toxicity has also resulted upon oral administration to both mouse and rat models $(5630 \mathrm{mg} / \mathrm{kg} /$ day in rats and $563 \mathrm{mg} / \mathrm{kg} /$ day in mice) [79]. Furthermore, human consumption of $250 \mathrm{mg}$ and $500 \mathrm{mg} 8: 1$ aqueous extract $W$. somnifera tablets at $750 \mathrm{mg} /$ day for 3 days has resulted in the adverse events of increased appetite, libido, and hallucinogenic effects with vertigo [80]. 


\section{Plants and plant constituents associated with renal toxicity}

Aristolochic acids I and II are found in Aristolochia fangchi, a member of the Aristolochiaceae family. Various animal studies presented in - Table 3 studied varying concentrations of each aristolochic acid and its effect on the body. Low doses produced proteinuria and glucosuria, while an increasing dosage produced necrosis and interstitial fibrosis [81-83]. In a 1992 human study, over $50 \%$ of patients experienced Belgian epidemic-nephropathy upper urothelial cancer due to long-term consumption of a weight loss pill. ESRD was also observed in $70 \%$ of aristolochic acid-poisoned patients, as well as hypertension, proteinuria, and glycosuria [82]. In 1996 case studies, aristolochic acid nephropathy was directly correlated to Chinese herb nephropathy. Women (age range from 27-42) consumed Chinese herbal weight loss pills for 13-23 months. Renal transplantation was necessary 9-27 months after the women stopped taking these pills. Patients in these case studies experienced renal and urinary tract degradation symptoms [83].

In another literature review of herbal medicine toxicities, aristolochic acid nephropathies such as Fanconi syndrome, renal failure, and tubular necrosis were observed in patients from Taiwan, Japan, and China [84]. Molecular analysis revealed that aristolochic acid is responsible for covalently binding to DNA in the nucleus, forming AL-DNA adducts that cause mutation or transcription error in protein synthesis that may cause these renal issues, particularly in cases of renal cell carcinoma [85]. Safrole is a compound present in sassafras and fennel essential oil that has been previously discussed as hepatotoxic but also has effects on the kidney. Many systemic effects were observed after two different groups of rats were administered either sassafras oil or safrole for 2 years. Oil comprised $0.117 \%$ of the diet in one group, while subjects in the second group were given pure safrole, which constituted $0.039 \%$ of their diet. Changes in kidney structure were noted postmortem [39].

Emodin, a toxic anthraquinone present in whole leaf A. barbadensis extract, has also demonstrated evidence for renal toxicity in rat models. In one study, the whole leaf extract administered orally to rats resulted in hypokalemia and renal failure [62].

\section{Plants and plant constituents associated with reproductive toxicity and developmental effects}

NDGA is a compound that has effects on the digestive and reproductive organ systems. NDGA is found in the leaves of chaparral (L. tridentata, Zygophyllaceae). A hydroethanolic extract of chaparral (4\% NDGA) was administered to hamsters. Numerous effects were observed, including growth retardation, irritability, aggressiveness, and hypoplasia of testicles and accessory sex glands [25].

Emodin, mentioned previously for its toxic effects in A. barbadensis, has also demonstrated reproductive toxicity in an animal study. In one rat model, oral administration of $100 \mathrm{mg} / \mathrm{kg}$ of whole leaf aloe extract produced reproductive inflammation and toxicity, notably, significant sperm damage [62].

L. meyenii, or maca, has been previously mentioned for its digestive and neurological toxicity. MTCA, an active ingredient in the maca root, has also been associated with causing reproductive distress in the form of altered menstrual cycles [65]. According to a literature review on clinical trials conducted involving maca, oral consumption of maca at $2.0-3.5 \mathrm{~g} /$ day for 1 to 3 months has resulted in adverse side effects of abdominal pain, gingival bleeding, and abnormal functioning of estrogen-dependent systems, such as endometriosis and breast cancer [26].

\section{Plants and plant constituents associated with toxicity of the endocrine system}

Safrole has been reported as hepatotoxic and toxic to kidneys in a study where rats were administered sassafras essential oil $(0.117 \%$ of diet) or pure safrole $(0.039 \%$ of diet) for 2 years. Subjects were noted as also having changes to various endocrine organs, including adrenals, thyroid, pituitary, and testes or ovaries [39].

\section{Plants and plant constituents associated with dermal toxicity}

Menthol is a well-known compound present in the Mentha genus of the Lamiaceae family. Mentha piperita (peppermint) is the origin of peppermint leaf essential oil. In a case study, a patient ingested over 40 drops of peppermint leaf oil, afterwards experiencing a chemical burn of the oral cavity and pharynx. The patient also showed tachycardia, tachypnea, and edema of the lips, tongue, and uvula [79].

\section{Discussion}

In conclusion, based on the case studies and experiments previously mentioned, there is an overwhelmingly vast degree to which HDSs may induce toxicity events to multiple body systems in both animals and humans. A total of 47 known compounds in 55 different plant species from 46 plant families demonstrated harmful side effects due to hepatotoxicity, cardiovascular toxicity, central nervous system toxicity, and digestive system toxicity. These studies provide relevant evidence to both the FDA and to the public consumer for the growing need of awareness of the degree of toxicity in HDSs. Furthermore, the accumulation of these studies speaks to an immediate need to hold manufacturers of these substances accountable for ensuring that the products they manufacture and release to the market do not pose a threat to public health. Moreover, this evidence speaks to the necessity for further in vitro bioassay, animal experimentation, and clinical investigation that may shed further light on the possible toxicity of commonly used HDSs.

While 49 known toxic plant compounds have been observed in this literature review, the investigation into the toxicity of plant supplements still has ground to cover. While case studies often demonstrate the toxic effects of active plant compounds, there is very little information provided in the literature about the exact minimum toxic or lethal doses in animals and humans. In fact, many studies and sources report only toxicity and adverse events resulting from herbal supplements after consumption of doses many times higher than the therapeutic doses recommended by supplement manufacturers. Furthermore, a significant amount of the literature considered for this review only established cytotoxicity using in vitro models. Additional studies are needed in order to establish relevancy to humans. Moreover, it may be necessary 
to initiate in vitro bioassays of other dietary supplement ingredients that may not show immediate adverse side effects, but are nonetheless very commonly used. These investigations may reveal as yet unknown toxicities or even advances in efficacy that these supplements may pose to public health that are unknown to manufacturers and/or the FDA. It is also prudent to consider that adverse events related to the consumption of botanical dietary supplements and other herbal medicinal drugs may be due to factors that cannot be easily identified by reading product labels for harmful plants or active ingredients. Adverse events may be related to several other factors, such as contamination with adulterants in the manufacturing process, ingredients benign by themselves that may react negatively with each other or other drugs, dosage variability, or the consumers themselves who may constitute special populations that may be at risk (i.e., children, pregnant women) [9]. These factors necessitate further inquiry and research to further understand the cause of adverse medical events connected to these products and mitigate prevention of such events in the future.

\section{Acknowledgements}

The authors are indebted to Auburn University Initiative in Cancer for financial support. The authors are also grateful to Dr. Joseph Betz from the Office of Dietary Supplements, National Institutes of Health, USA, and Dr. Robin Marles from Health Canada for reviewing and providing helpful critiques to the manuscript. E. Lopez thanks Auburn University Undergraduate Fellowship Program for continued support in her Pharmaceutical Sciences research endeavors. Thanks to King Abdulaziz University for a Master's degree scholarship to A. J. Almalki.

Conflict of Interest

The authors declare no conflict of interest.

\section{References}

[1] Ekor M. The growing use of herbal medicines: issues relating to adverse reactions and challenges in monitoring safety. Frontiers Pharm 2013; 4: 177

[2] Camire ME, Kantor MA. Dietary supplements: nutritional and legal considerations. Food Tech 1999; 7: 87-96

[3] Barnes PM, Bloom B, Nahin R. CDC National Health Statistics Report \#12. Complementary and Alternative Medicine Use Among Adult Child. Available at https://www.ncbi.nlm.nih.gov/pubmed/19361005. Accessed October 8, 2016

[4] Nahin RL, Barnes PM, Stussman B], Bloom B. Costs of complementary and alternative medicine (CAM) and frequency of visits to CAM practitioners: United States, 2007. Nat Health Stat Report 2009; 18: 1-14

[5] Global Industry Analysts, Inc. (GIA). Herbal Supp Rem Mark; 2015. Available at http://www.strategyr.com/MarketResearch/Herbal_ Supplements_and_Remedies_Market_Trends.asp/. Accessed February 2, 2017

[6] U.S. Food and Drug Administration. Background on the FDA Food Safety Modernization Act (FSMA); 2018. Available at https://www.fda.gov/ NewsEvents/PublicHealthFocus/ucm239907.htm. Accessed December 28, 2017

[7] National Center for Complementary and Integrative Health. Ephedra. National Institutes of Health. U.S. Department of Health and Human Ser- vices; 2015. Available at https://nccih.nih.gov/health/ephedra. Accessed November 30, 2016

[8] Lewis CJ. Safety alerts and advisories - FDA advises dietary supplement manufacturers to remove comfrey products from the market; 2001. Available at https://www.fda.gov/Food/RecallsOutbreaksEmergencies/ SafetyAlertsAdvisories/ucm111219.htm. Accessed April 14, 2017

[9] Farina EK, Austin KG, Lieberman HR. Concomitant dietary supplement and prescription medication use is prevalent among US adults with doctor-informed medical conditions. J Acad Nutr Diet 2014; 114: 17841790.e2

[10] Smith T, Kimberly K, Eckl V, Morton C, Stredney R. Herbal supplement sales in US increase $7.7 \%$ in 2016. HerbalGram: Amer Botan Counc 2017; 115: 11

[11] Dong X. Emodin: a Review of its Pharmacology, Toxicity and Pharmacokinetics. New York City: John Wiley \& Sons, Ltd.; 2016

[12] Bottenberg MM, Wall GC, Harvey RL, Habib S. Oral aloe vera-induced hepatitis. An Pharmacother 2007; 41: 1740-1743

[13] Lee J, Lee MS, Nam KW. Acute toxic hepatitis caused by an Aloe vero preparation in a young patient: a case report with a literature review. Korean J Gastro 2014; 64: 54-58

[14] Yang HN, Kim DJ, Kim YM, Kim BH, Sohn KM, Choi MJ, Choi YH. Aloe-induced toxic hepatitis. J Korean Med Sci 2010; 3: 492-495

[15] Toxicology Data Network. Anthraquinone. National Institutes of Health 2006. Available at https://toxnet.nlm.nih.gov/cgibin/sis/search/a?dbs\% 2Bhsdb\%3A\%40term\%2B\%40DOCNO\%2B2074. Accessed April 23, 2017

[16] Dai JP, Wang QP, Su Y, Gu LM, Zhao Y, Chen XX, Chen C, Li WZ, Wang GF, Li KS. Emodin inhibition of influenza $A$ virus replication and influenza viral pneumonia via the Nrf2, TLR4, p38/JNK and NF-kappaB pathways. Molecules 2017; 22: 1754/1-1754/17

[17] Zhang Z, Chen S, Mei H. Ginkgo biloba leaf extract induces DNA damage by inhibiting topoisomerase II activity in human hepatic cells. Sci Rep 2015; 5: 14633

[18] National Center for Complementary and Integrative Health. Ginkgo. National Institutes of Health; 2017. Available at https://nccih.nih.gov/ health/ginkgo/ataglance.htm. Accessed April 23, 2017

[19] Gardner Z, McGuffin M. American Herbal Products Association's botanical Safety Handbook, 2nd ed. Boca Raton, FL: CRC Press; 2013: 834-837

[20] Bach N, Thung SN, Schaffner F. Comfrey herb tea-induced hepatic venoocclusive disease. Amer ] Med 1989; 87: 97-99

[21] Clinical and Research Information on Drug-induced Liver Injury. Comfrey. LiverTox 2014. Available at https://livertox.nih.gov/Comfrey.htm. Accessed April 23, 2017

[22] Fu PP, Yang YC, Xia Q, Chou MC, Cui YY, Lin G. Pyrrolizidine alkaloids-tumorigenic components in Chinese herbal medicines and dietary supplements. J Food Drug Anal 2002; 10: 198-211

[23] European Medicines Agency - Committee of Herbal Medicinal Products. Public statement on contamination of herbal medicinal products/traditional herbal products with pyrrolizidine alkaloids. Available at http:// www.ema.europa.eu/docs/en_GB/document_library/Public_statement |2016/06/WC500208195.pdf. Accessed April 24, 2017

[24] Gardner Z, McGuffin M. American Herbal Products Association's botanical Safety Handbook, 2nd ed. Boca Raton, FL: CRC Press; 2013: 900-902

[25] Gardner Z, McGuffin M. American Herbal Products Association's botanical Safety Handbook, 2nd ed. Boca Raton, FL: CRC Press; 2013: 498-502

[26] Arteaga S, Andrade-Cetto A, Cárdenas R. Larrea tridentata (Creosote bush), an abundant plant of Mexican and US-American deserts and its metabolite nordihydroguaiaretic acid. J Ethnopharm 2005; 98: 231-239

[27] Moro PA, Cassetti F, Giugliano G, Falce MT, Mazzanti G, Menniti-Ippolito F, Raschetti R, Santuccio C. Hepatitis from greater celandine (Chelidonium majus L.): review of literature and report of a new case. J Ethnopharm 2009; 124: 328-332 
[28] Teschke R, Glass X, Schulze J. Herbal hepatotoxicity by greater celandine (Chelidonium majus): causality assessment of 22 spontaneous reports. Reg Tox Pharm 2011; 61: 282-291

[29] Teschke R, Wolff A, Frenzel C, Schulze J, Eickhoff A. Herbal hepatotoxicity: a tabular compilation of reported cases. Liver Int 2012; 32: $1543-$ 1556

[30] Madyastha KM, Raj CP. Effects of Menthofuran, a Monoterpene Furan on Rat Liver microsomal Enzymes, in vivo. Amsterdam: Elsevier; 1994: 119125

[31] Woolf A. Essential Oil Poisoning. United Kingdom: Taylor \& Francis Group; 1999: 721-727

[32] Chalasani N Vuppalanchi R, Navarro V, Fontana R, Bonkovsky H, Barnhart $\mathrm{H}$, Kleiner DE, Hoofnagle $\mathrm{JH}$. Acute liver injury due to flavocoxid (Limbrel), a medical mood for osteoarthritis: a case series. Ann Intern Med 2012; 156: 857-860

[33] Bedada W, Andres F, Engidawork E, Pohanka A, Beck O, Bertilsson L, Llerena A, Aklilu E. The psychostimulant khat (Catha edulis) inhibits CYP2D6 enzyme activity in humans. J Clin Psychopharm 2015; 35: 694-699

[34] Clinical and Research Information on Drug-induced Liver Injury. Khat. LiverTox 2013. Available at https://livertox.nlm.nih.gov/Khat.htm. Accessed April 23, 2017

[35] Forbes MP, Raj AS, Martin J, Lampe G, Powell EE. Khat-associated hepatitis. Med J Aust 2013; 199: 498-499

[36] Stuyt R, Willems SM, Wagtmans M], van Hoek B. Hepatotoxicity of khat chewing. Liver Int 2001; 31: 434-436

[37] Kamalu BP. Pathological changes in growing dogs fed on a balanced cassava (Manihot esculenta Crantz) diet. Br J Nutr 1993; 69: 921-934

[38] Kangas-Dick A, Khan U, Awoniyi O, Waqar S, Tun NN, Viswanathan K, Wong C. A case of chronic calcific nonalcoholic pancreatitis. Case Reps Gastrointest Med 2016; 2016: 2963681

[39] U.S. Food and Drug Administration. International drug scheduling: convention on psychotropic substances 2005. Available at https://www.fda. gov/ohrms/dockets/98fr/05-23958.htm. Accessed February 16, 2018

[40] Funk JL, Frye JB, Oyarzo JN, Zhang H, Timmermann BN. Anti-arthritic effects and toxicity of the essential oils of turmeric (Curcuma longa L.). J Agric Food Chem 2010; 58: 842-849

[41] Chopra A, Saluja M, Tillu G, Venugopalan A, Narsimulu G, Sarmukaddam S, Patwardhan B. Evaluating higher doses of Shunthi - Guduchi formulations for safety in treatment of osteoarthritis knees: A Government of India NMITLI arthritis project. J Ayurvedic Integ Med 2012; 3: 38-44

[42] Levorato S, Dominici L, Fatigoni C, Zadra C, Pagiotti R, Moretti M, Villarini M. In vitro toxicity evaluation of estragole-containing preparations derived from Foeniculum vulgare Mill. (fennel) on HepG2 cells. Food Chem Toxicol 2018; 111: 616-622

[43] Probert PM, Palmer JM, Alhusainy W, Amer AO, Rietjens IM, White SA, Jones DE, Wright MC. Progenitor-derived hepatocyte-like (B-13/H) cells metabolise 1'-hydroxyestragole to a genotoxic species via a SULT2B1dependent mechanism. Toxicol Lett 2016; 243: 98-110

[44] van den Berg SJ, Alhusainy W, Restani P, Rietjens IM. Chemical analysis of estragole in fennel based teas and associated safety assessment using the Margin of Exposure (MOE) approach. Food Chem Toxicol 2014; 65: $147-154$

[45] Gardner Z, McGuffin M. American Herbal Products Association's botanical Safety Handbook, 2nd ed. Boca Raton, FL: CRC Press; 2013: 786-788

[46] Haller CA, Jacob P, Benowitz NL. Pharmacology of ephedra alkaloids and caffeine after single-dose dietary supplement use. Clin Pharmacol Ther 2002; 7: 421-432

[47] Haller C, Benowitz N. Adverse cardiovascular and central nervous system events associated with dietary supplements containing ephedra alkaloids. N Engl J Med 2000; 343: 1833-1838
[48] Gardner Z, McGuffin M. American Herbal Products Association's botanical Safety Handbook, 2nd ed. Boca Raton, FL: CRC Press; 2013: 5-7

[49] Ammar EM, Abdelal M, Afifi AM. Role of central cholinergic and adrenergic receptors in mediating the central arrhythmogenic effect of aconitine. Acta Pharm Jug 1976; 26: 223-228

[50] Parker AJ, Lee JB, Redman J, Jolliffe L. Strychnine poisoning: gone but not forgotten. Emerg Med J 2011; 28: 84-85

[51] Prat S, Hoizey G, Lefrancq T, Saint-Martin P. An unusual case of strychnine poisoning. J Forensic Sci 2015; 60: 816-817

[52] Khan I, Kant C, Sanwaria A, Meena L. Acute cardiac toxicity of nerium oleander/indicum poisoning (kaner) poisoning. Heart Views 2010; 11 : 115-116

[53] Osterloh J. Oleander interference in the digoxin radioimmunoassay in a fatal ingestion. JAMA 1982; 247: 1596-1597

[54] Boswell BR, Dorweiler MA, Erbs NC, Caplan JP. A case of Nerium oleander toxicity: a thorny predicament. Psychosomatics 2014; 54: 379-381

[55] Gupta A, Joshi P, Jortani SA, Valdes R jr., Thorkelsson T, Verjee Z, Shemie S. A case of nondigitalis cardiac glycoside toxicity. Ther Drug Monit 1997; 19: $711-714$

[56] Abbassi MH, Fatima S, Khawar MB, Naz N, Mujeeb KA, Akhtar T, Sheikh $\mathrm{N}$. Dose-dependent acute phase response of aqueous leaf decoction of Nerium oleander in Wistar rats. J Biol Regul Homeost Agents 2017; 31: 985-989

[57] Gardner Z, McGuffin M. American Herbal Products Association's botanical Safety Handbook, 2nd ed. Boca Raton, FL: CRC Press; 2013: 633-635

[58] Hess A, Sullivan D. Potential for toxicity with use of bitter orange extract and guarana for weight loss. Cedarville, Ohio: Pharmacy Practice Faculty Publications; 2005: 2-3

[59] Canders CP, Stanford SR, Chiem AT. A dangerous cup of tea. Wilderness Environ Med 2014; 25: 111-112

[60] Subbiah MT, Ravi YM. Studies on the nature of anti-platelet aggregatory factors in the seeds of the amazonian herb Guarana (Paullinia cupana). Intl J Vit Nutr Res 2008; 78: 96-101

[61] Haller CA, Duan M, Benowitz NL, Jacob P. Concentrations of ephedra alkaloids and caffeine in commercial dietary supplements. J Anal Toxicol 2004; 28: 145-151

[62] Dunnick JK, Nyska A. The toxicity and pathology of selected dietary herbal medicines. Toxicol Pathol 2012; 41: 374-386

[63] Kumar S, Yadav JP. Ethnobotanical and pharmacological properties of Aloe vera: a review. J Med Plants Res 2014; 8: 1387-1398

[64] Guo X, Nan M. Aloe vera: A review of toxicity and adverse clinical effects. J Environ Sci Health C Environ Carcinog Ecotoxicol Rev 2016; 34: 77-96

[65] Gardner Z, McGuffin M. American Herbal Products Association's botanical Safety Handbook, 2nd ed. Boca Raton, FL: CRC Press; 2013: 799-801

[66] Gosselin RE, Smith RP, Hodge HC. Clinical Toxicology of commercial Products, 5th ed. Baltimore, MD: Williams \& Wilkins; 1984

[67] Delbart F, Brams M, Gruss F, Noppen S, Boland S, Chaltin P, Brandao-Neto S, von Delft F, Touw WG, Joosten RP, Liekens S, Tytgat J, Ulens C. An allosteric binding site of the $\alpha 7$ nicotinic acetylcholine receptor revealed in a humanized acetylcholine-binding protein. J Biochem 2018; 293: 25342545

[68] Jacobs KL. United States Pharmacopeia (USP) Admission Evaluation of European Elderberry dry Extract. Rockville, Maryland: Dietary Supplements Admission Evaluations Joint Standards-Setting Subcommittee; 2017: 46-47

[69] Corazza O, Martinotti G, Santacroce R, Chillemi E, Giannantonio MD, Schifano F, Cellek S. Sexual enhancement products for sale online: raising awareness of the psychoactive effects of yohimbine, maca, horny goat weed, and Ginkgo biloba. Biomed Res Int 2014; 2014: 841798

[70] Myeong SL. Maca (Lepidium meyenii) for treatment of menopausal symptoms: a systematic review. Maturitus 2011; 70: 227-233 
[71] Gardner Z, McGuffin M. American Herbal Products Association's botanical Safety Handbook, 2nd ed. Boca Raton, FL: CRC Press; 2013: 771-773

[72] Gardner Z, McGuffin M. American Herbal Products Association's botanical Safety Handbook, 2nd ed. Boca Raton, FL: CRC Press; 2013: 179-182

[73] Datta S, Mahdi F, Ali Z, Khan IA, Jekabsons MB, Nagle DG, Zhou YD. Toxins from botanical dietary supplements: blue cohosh components disrupt mitochondrial membrane integrity and impair cellular respiration. Planta Medica 2013; 79: PH23

[74] Rader JI, Pawar RS. Primary constituents of blue cohosh: quantification in dietary supplements and potential for toxicity. Anal Bioanal Chem 2013; 13: 4409-4417

[75] U.S. Food and Drug Administration. Caffeine and kids: FDA takes a closer look. 2013. Available at https://www.fda.gov/ForConsumers/Consumer Updates/ucm350570.htm. Accessed March 13, 2018

[76] Netto AB, Netto CM, Mahadeyan A, Taly AB, Agadi JB. Tropical ataxic neuropathy - a century old enigma. Neurol India 2016; 6: 1151-1159

[77] Rivadeneyra-Domínguez E, Vázquez-Luna A, Rodríguez-Landa JF, DíazSobac R. Neurotoxic effect of linamarin in rats associated with cassava (Manihot esculenta Crantz) consumption. Food Chem Toxicol 2013; 59 : 230-235

[78] Ballantyne B, Snellings WM. Triethylene glycol $\mathrm{HO}(\mathrm{CH} 2 \mathrm{CH} 2 \mathrm{O}) 3 \mathrm{H}$. J Appl Toxicol 2007; 27: 291-299
[79] Wang J, van der Heijden R, Spruit S, Hankermeier T, Chan K, van der Greef J, Xu G, Wang M. Quality and safety of Chinese herbal medicines guided by a systems biology perspective. J Ethnopharm 2009; 126: 31 41

[80] Raut AA, Rege NN, Tadvi FM, Solanki PV, Kene KR, Shirolkar SG, Vaidya AB. Exploratory study to evaluate tolerability, safety, and activity of Ashwagandha (Withania somnifera) in healthy volunteers. J Ayurveda Integ Med 2012; 3: 111-114

[81] Jadot ICA, Declèves AE, Nortier ], Caron N. An integrated view of aristolochic acid nephropathy: update of the literature. Int J Mol Sci 2017; 18: 297

[82] Schmeiser H, Bieler C, Wiessler M, van Ypersele de Strihou C, Cosyns JP. Detection of DNA adducts formed by aristolochic acid in renal tissue from patients with Chinese herbs nephropathy. Cancer Res 1996; 56 : 2025-2028

[83] Debelle F, Vanherweghem J, Nortier J. Aristolochic acid nephropathy: a worldwide problem. Kidney Int 2008; 74: 158-169

[84] Gardner Z, McGuffin M. American Herbal Products Association's botanical Safety Handbook, 2nd ed. Boca Raton, FL: CRC Press; 2013: 561-564

[85] Hoang ML, Chen CH, Chen PC, Roberts NJ, Dickman KG, Yun BH, Turesky RJ, Pu YS, Vogelstein B, Papadopoulas N, Grollman AP, Kinzler KW, Rosenquist TA. Aristolochic acid in the etiology of renal cell carcinoma. Cancer Epidemiol Biomarkers Prev 2016; 25: 1600-1608 